\title{
25 Research Soure \\ Degradation Characteristics of Pinoxaden by Acinetobacter and Prediction of Related Genes
}

\author{
Fengshan Yang \\ Heilongjiang University \\ Yuning Wei \\ Heilongjiang University \\ Cong Sun \\ Heilongjiang University \\ Mingrui Yuan \\ Heilongjiang University \\ Weimin Zeng \\ Heilongjiang University \\ Chunguang Liu ( 2005013@hlju.edu.cn ) \\ Heilongjiang University https://orcid.org/0000-0002-6186-6022 \\ Haiyan Fu \\ Heilongjiang University
}

\section{Research Article}

Keywords: acinetobacter, degrading bacteria, degradation rate, degradation genes, pinoxaden, genome sequencing

Posted Date: March 1st, 2022

DOI: https://doi.org/10.21203/rs.3.rs-1375498/v1

License: (c) (1) This work is licensed under a Creative Commons Attribution 4.0 International License.

Read Full License 


\section{Abstract}

In order to improve crop yield per unit area, pinoxaden was widely used in weed control in the field to better degrade the residual pinoxaden in the soil. In this experiment, 14 strains were domesticated and isolated from soil samples using pinoxaden as the only carbon and nitrogen source, and the highly degraded strain was T4P20-1. The effects of different $\mathrm{pH}$ values, inoculation amount and culture time on the growth and degradation rate of strain T4P20-1 were studied. The optimal growth conditions of strain T4P20-1 were determined, and the degradation rate reached $92.23 \%$. The morphological characteristics of strain T4P20-1 were determined by optical microscope. The strain T4P20-1 was identified as Acinetobacter Pittii by physiological and biochemical characteristics and 16S rDNA homology analysis, and the nucleic acid sequence was submitted to Gentbank to obtain the accession number MW350066. Through gene sequencing, the whole genome framework of strain T4P20-1 and database annotations of GO, KEGG, COG, CAZymes and PHI were obtained. Meanwhile, genes related to herbicide degradation were predicted by gene functional annotations. There was a negative correlation between herbicide and seed germination rate, bud length and root length of maize susceptible to subsequent crop. In conclusion, the strains screened in this study have certain remediation effects on soil contaminated by pinoxaden. It provides a new choice for the degradation of pinoxaden in the future. It can increase crop yields and reduce food security risks.

\section{Introduction}

Pinoxaden is an endosuction conductive phenyl pyr pinoxaden herbicide discovered, developed and produced by Syngenta. Its molecular formula is C23H32N2O4. Its chemical structure formula (Figure S1).

After entering the environment, pinoxaden is easy to degrade and metabolize. There are more than 20 kinds of metabolites, which can be detected in animals and plants. $5 \%$ EC is a slightly toxic herbicide, which has moderate irritation to white rabbit skin and eyes. pinoxaden is difficult to photolysis, difficult to leach in soil, easy to be degraded, adsorbed and volatilized, has low biological toxicity to the environment, has a certain impact on the tested plants [1,2], and is easy to be degraded in water sediment [3]. The median lethal concentrations of $5 \%$ pinoxaden EC to rainbow trout, Daphnia, algae, birds and silkworm were $24 \mathrm{mg} / \mathrm{L}, 4 \mathrm{mg} / \mathrm{L}, 4.17 \mathrm{mg} / \mathrm{L}, 4780.3 \mathrm{mg} / \mathrm{kg}$ and $4000 \mathrm{mg} / \mathrm{L}$ respectively. It has low toxicity to organisms in the environment and medium toxicity to aquatic organisms such as algae, which has a certain impact on the tested plants $[4,5]$.

\section{Material And Methods}

\section{Experimental materials}

Test soil sample: Soil sample number (Table S1). After screening, the test soil sample was stored in the refrigerator at $4^{\circ} \mathrm{C}$. 
Reagent: 95\% pinoxaden (Syngenta crop protection Co., Ltd., Switzerland); Chromato-graphic grade methanol (Shandong Yuwang, chromatographic pure); Dichloromethane (Tianjin Guangfu, analytical purity).

Medium: basic inorganic salt medium (MSM): $\mathrm{K}_{2} \mathrm{HPO}_{4} 1.79 \mathrm{~g}, \mathrm{KH}_{2} \mathrm{PO}_{4} 0.45 \mathrm{~g}, \mathrm{MgSO}_{4} \cdot 7 \mathrm{H}_{2} \mathrm{O} 0.2 \mathrm{~g}, \mathrm{NaCl}$ $0.4 \mathrm{~g}$, distilled water $1000 \mathrm{~mL}$, pH 7.0. Solid medium: $1.5 \sim 2.0 \%$ AGAR powder.; Luria Bertani (LB) medium: tryptone $10.0 \mathrm{~g}$, yeast extract $5.0 \mathrm{~g}, \mathrm{NaCl} 10.0 \mathrm{~g}$, distilled water $1000 \mathrm{~mL}, \mathrm{pH} 7.0,121^{\circ} \mathrm{C}$, autoclave for $15 \mathrm{~min}$.

Mother liquor configuration: weigh $0.5 \mathrm{~g}$ of pinoxaden standard, put it into a $10 \mathrm{~mL}$ volumetric flask, fix the volume with chromatographic grade methanol, and pass $0.45 \mu \mathrm{L}$ organic filter membrane, keep for standby.

Preparation of bacterial suspension: select the purified single colony, inoculate it into the test tube containing $5 \mathrm{~mL}$ LB liquid medium, shake it at $30{ }^{\circ} \mathrm{C}$ for $160 \mathrm{rpm}$, culture it for $12 \mathrm{~h}$, activate it, and take the activated strain $100 \mu \mathrm{L}$. Place it in a 96 well plate to measure the OD value, take samples according to the $\mathrm{OD}_{600}$ value, place it in a $1.5 \mathrm{~mL}$ centrifuge tube, $16,000 \mathrm{G}$, centrifuge for $5 \mathrm{~min}$, discard the supernatant, add sterile $0.9 \%$ normal saline, shake with votex for $1 \mathrm{~min}$, centrifuge again, discard the supernatant, add sterile $0.9 \%$ normal saline, adjust $\mathrm{OD}_{600}=1.0$ to make a bacterial suspension.

\section{Enrichment, domestication, culture, separation and purification of highly effective degrading bacteria}

The pinoxaden degrading strain was acclimated and isolated by enrichment culture method. $5 \mathrm{~g}$ soil sample, $25 \mathrm{~mL}$ inorganic salt liquid medium and an appropriate amount of pinoxaden were added to a 50 $\mathrm{mL}$ triangular flask to make the concentration of pinoxaden in the triangular flask reach $200 \mathrm{mg} / \mathrm{L}$. it was cultured in a constant temperature shaking table at $30{ }^{\circ} \mathrm{C} 180 \mathrm{R} / \mathrm{min} .2 .5 \mathrm{~mL}$ of culture was taken every 5 days and inoculated into a new inorganic salt liquid medium, At the same time, the content of pinoxaden in the culture medium was increased by $200 \mathrm{mg} / \mathrm{L}$ and domesticated for 5 weeks until the concentration of pinoxaden in the culture medium reached $1000 \mathrm{mg} / \mathrm{L}$. the enriched cultures were gradient diluted with sterile water $\left(10^{-1}, 10^{-2}, 10^{-3}, 10^{-4}, 10^{-5}, 10^{-6}, 10^{-7}, 10^{-8}\right)$ and coated in the inorganic salt solid medium added with pinoxaden. Culture in a constant temperature incubator at $30{ }^{\circ} \mathrm{C}$ for 3 days, select colonies with different colors and shapes for purification, add the purified strain to the LB medium containing $1 \mathrm{~mL}$ for shaking culture, when the $\mathrm{OD}$ value reaches $1.0,16,000 \mathrm{G}$, centrifuge for 5 min, discard the supernatant, add $70 \%$ glycerol, suck and mix well, and store at $-20{ }^{\circ} \mathrm{C}$.

\section{Determination of growth curve, addition recovery rate and degradation rate of highly degrading bacterial strain}

Take $20 \mu \mathrm{L}$ of cultured bacterial suspension was added to $180 \mu \mathrm{L}$ of pinoxaden inorganic salt medium (concentration of pinoxaden was $25 \mathrm{mg} / \mathrm{L}, 50 \mathrm{mg} / \mathrm{L}, 75 \mathrm{mg} / \mathrm{L}$ ) and LB liquid medium, and four replicates were tested every $12 \mathrm{~h}$. Bioscreen was used for $72 \mathrm{~h}$. The strain growth curve was plotted. 
Add $1 \mathrm{~mL}$ of culture medium, $0.25 \mathrm{~g} \mathrm{NaCl}$ and $5 \mathrm{~mL} \mathrm{CH} \mathrm{Cl}_{2}$ into $10 \mathrm{~mL}$ centrifuge tube respectively, and shake on vortex for $1 \mathrm{~min}$; Take out the upper layer and put it into a new $10 \mathrm{~mL}$ centrifuge tube, add $1 \mathrm{~mL}$ $\mathrm{CH}_{2} \mathrm{Cl}_{2}$, vortex oscillate for $1 \mathrm{~min}$, take the lower organic phase and place it in the first corresponding centrifuge tube, continue to add $1 \mathrm{~mL} \mathrm{CH} \mathrm{Cl}_{2}$ into the second $10 \mathrm{~mL}$ centrifuge tube and oscillate for $1 \mathrm{~min}$, take the organic phase and place it in the first centrifuge tube; Add $0.2 \mathrm{~g}$ anhydrous $\mathrm{Na}_{2} \mathrm{SO}_{4}$ to the combined first centrifugal tube and shake, put the upper liquid into a $10 \mathrm{~mL}$ volumetric flask, put the volumetric flask into a $50{ }^{\circ} \mathrm{C}$ water bath, and evaporate $\mathrm{CH}_{2} \mathrm{Cl}_{2}$; Dilute to $10 \mathrm{~mL}$ with chromatographic grade methanol, shake with ultrasonic for $30 \mathrm{~min}$, pass through $0.45 \mu \mathrm{m}$ organic filter membrane, put it in $2 \mathrm{~mL}$ centrifuge tube, store it in refrigerator at $4{ }^{\circ} \mathrm{C}$ and wait for measurement.

Add $5 \mathrm{~mL}$ of pinoxaden inorganic salt liquid medium ( $25 \mathrm{mg} / \mathrm{L}, 50 \mathrm{mg} / \mathrm{L}, 75 \mathrm{mg} / \mathrm{L}$ ) and $50 \mathrm{~mL}$ into the test tube respectively bacteria suspension, mark the liquid level before shaking, and culture it in a constant temperature shaking table at $30^{\circ} \mathrm{C} 200 \mathrm{rpm}$ for 5 days. $\mathrm{CG}$ in the blank control group shall be cultured together with the test tube receiving bacteria. Before sampling, the liquid level shall be supplemented according to the records, and the culture solution shall be extracted for high performance liquid chromatography (the chromatographic column is INERTSIL ODS-3 $5 U M(5 \mu \mathrm{m}, 4.6 \times 250 \mathrm{~mm})$, the injection volume is $20 \mu \mathrm{L}$ ), and its degradation ability is measured. Set the liquid chromatographic conditions of pinoxaden (column temperature: $40^{\circ} \mathrm{C}$; flow rate: $1.0 \mathrm{~mL} / \mathrm{min}$; mobile phase: acetonitrile: water $(0.05 \%$ phosphoric acid aqueous solution $)=65: 35(\mathrm{~V}: \mathrm{V})$; detection wavelength: $260 \mathrm{~nm})$. After the above conditions are set, take the mother liquor of pinoxaden and dilute it to $12.5 \mathrm{mg} / \mathrm{L}, 7.5 \mathrm{mg} / \mathrm{L}, 5$ $\mathrm{mg} / \mathrm{L}, 2.5 \mathrm{mg} / \mathrm{L}$ and $1 \mathrm{mg} / \mathrm{L}$ respectively, and draw the standard curve of pinoxaden, HPLC analysis was carried out ac-cording to the chromatographic conditions. The determination of the addition recovery rate and the calculation formula of the degradation rate are as follows:

Addition recovery $(\%)=($ measured $/$ addition $) \times 100 \%(1)$

Degradation rate $(\%)=[1$ - (treatment measured / control measured $)] \times 100 \%(2)$

\section{Identification of highly degrading bacterial strain}

Gram staining: carry out Gram staining on the strain, and then determine the characteristics of the strain under the oil microscope of the optical microscope. Refer to the three-step Gram staining [6-8], prepare LB solid medium, dilute and coat the purified strain on the medium respectively, and observe the size, edge, transparency, color, shape and other characteristics of the single colony after cultured in the incubator at $30{ }^{\circ} \mathrm{C}$ for 72 hours.

Biochemical identification: use biochemical identification tube for identification, inoculate the purified strain into nutrient broth medium, culture at $37^{\circ} \mathrm{C}$ for $18-24$ hours, and absorb $50 \mu \mathrm{L}$ broth cultures were added into micro vials and cultured in $35-37^{\circ} \mathrm{C}$ incubators. For identification of physiological and biochemical characteristics, refer to Berger's Manual for identification of bacteria (Ninth Edition) [8] and manual for identification of common bacteria [9]. 
16S rDNA sequence identification: 16S rDNA universal primers were used to amplify the DNA of the isolated strain. General primers (Table S2), reaction systems and circulation conditions (Table S3) for strain identification. PCR products were detected by $1 \%$ agarose gel electrophoresis. Finally, the purified PCR product was sent to bioengineering Shanghai company for gene sequencing. The 16S rDNA sequence was stored in the ribosomal database: http://rdp.cme.msu.edu/index.jsp. And submit it to NCBI to obtain the login number.

\section{Determination of growth characteristics of highly degrading bacterial strain under different $\mathrm{pH}$, inoculation amount and culture time}

Pick out the purified single colony, inoculate it into a test tube containing $5 \mathrm{~mL}$ LB liquid medium, shake it at $30{ }^{\circ} \mathrm{C}, 160 \mathrm{R} / \mathrm{min}$, culture it for $12 \mathrm{~h}$, activate it, and take the activated strain $100 \mu 50$. Put it into a 96 well plate to measure $\mathrm{OD}_{600}$, take samples according to the $\mathrm{OD}_{600}$ value, put it into a $1.5 \mathrm{~mL}$ centrifuge tube, $5000 \mathrm{R} / \mathrm{min}$, centrifuge for $5 \mathrm{~min}$, discard the supernatant, add sterile $0.9 \%$ normal saline, shake with votex for $1 \mathrm{~min}$, centrifuge again, discard the super-natant, add sterile $0.9 \%$ normal saline, adjust $\mathrm{OD}_{600}=1.0$ to make a bacterial suspension. Determine the growth characteristics of high-efficiency degrading bacteria strain at different $\mathrm{pH}$ : take $10 \%$ bacterial suspension and add it to the inorganic salt liquid medium containing $75 \mathrm{mg} / \mathrm{L}$ of pinoxaden at $\mathrm{pH}=6.0,7.0$ and 8.0 for three repetitions. Set one without strain as the control group, test it every 12 hours, test it with Bioscreen for 72 hours, and draw the strain growth curve.

Repeat the above steps to determine the growth characteristics of high-efficiency degrading bacteria strain under different inoculation amounts: Take $1 \%, 5 \%$ and $10 \%$ bacterial suspension and add it to the liquid medium containing $75 \mathrm{mg} / \mathrm{L}$ pinoxaden inorganic salt for three repetitions. Set one without adding strain as the control group, detect it every 12 hours, detect it with Bioscreen for 72 hours, and draw the strain growth curve.

Repeat the above steps to measure the growth characteristics of high-efficiency degrading bacteria strain under different culture times: take $10 \%$ of the bacterial suspension and add it to the liquid medium containing $75 \mathrm{mg} / \mathrm{L}$ pinoxaden inorganic salt for three repetitions, set one without adding the strain as the control group, detect it every 12 hours, detect it with Bioscreen for 72 hours, determine the residue by $\mathrm{HPLC}$ and calculate the degradation rate, The growth curve and degradation curve of the strain were drawn.

\section{Determination of degradation capacity of highly degrading bacterial strain}

The bioassay test method of strain degradation ability is as follows: the strain with high degradation rate is connected to the pinoxaden inorganic salt medium with sensitive concentration, shake culture at $30{ }^{\circ} \mathrm{C}$, and applied to the sensitive crop corn seeds according to the above method. This is the treatment group. In addition, sterile water is set as the blank group, and the herbicide inorganic salt medium without 
bacteria is set as the control group. After each batch of treated corn seeds grew for 6 days, the germination rate, bud length and root length were observed and recorded.

\section{Whole genome sequencing of degrading strain}

Genomic DNA was extracted by SDS. DNA purity and integrity were analyzed by agarose gel electrophoresis, and DNA concentration was quantified by Qubit. Each sample contained $1 \mu \mathrm{g}$ of $300 \mathrm{bp}$ DNA fragment randomly crushed with covaris ultrasonic crusher. Complete DNA library was prepared by terminal repair, A-tail addition, sequencing linking, purification, PCR amplification and other methods. After the library was constructed, Qubit2.0 was used for pre-liminary quantification, diluted to $2 \mathrm{ng} / \mathrm{uL}$ and Agilent 2100 was used to detect the library insert fragment. After the inserted fragment met the expectation, q-PCR method was used to accurately quantify the effective concentration of the library to ensure the quality of the library. After the library was identified, the whole genome of strain T4P20-1 was sequenced using Illumina-Hiseq platform according to the requirements of effective concentration and target data volume. All high-quality paired reads are assembled into many scaffolds using SPAdes (V3.13.0) software. Finally, scaffolds larger than 500bp were selected for follow-up analysis. The specific steps of genomic component prediction are as follows: 1) Use Prokka (1.13.7) software to retrieve relevant coding genes. 2) Use RepeatMasker (V4.0.9) to predict the scattered repeat sequence. 3) Transport RNA (tRNA) genes were predicted by tRNAscan SE. Ribosomal RNA (rRNA) genes were analyzed with rRNAmmer (1.2). 4) Protein signal peptides were predicted by SignalP (V5.0 software). And TMHMM (v2.0) (http://www.cbs.dtu.dk/services/TMHMM/) using the tools of the annotations, whether to contain transmembrane protein sequence structure choice across with signal peptide structure and membrane structure protein as a secreted protein. GeneWise is used to look for pseudogenes. We used four databases to predict gene function. They are GO, KEGG, COG and CAZymes.

\section{Statistical analysis methods}

SPSS 20.0 statistical software was used for statistical analysis. The Ducan's multiple range test was used. The significance level passed the LSD homogeneity test. All tests were subjected to three biological repetitions, and the significance level was $p<0.05$. The differences between the treatment group and the blank group of the control group were analyzed and compared to find the correlation with the addition of microbial degrading bacteria.

\section{Results}

\section{Enrichment, domestication, culture, separation and purification of highly effective degrading bacteria}

Enrichment culture was carried out through the inorganic salt medium added with pinoxaden, and the bacterial strains with transparent circles in the medium added with herbicide in the in-organic salt were initially screened out, and further purification was carried out on LB solid medium. Forty-five highly degrading strains (Table S4) were isolated from soil samples planted with rice, corn, wheat, potato, 
cotton, peanut and apple in Heilongjiang and Shandong provinces, among which 14 strains were capable of degrading pinoxaden.

\section{Determination of growth curve of efficient degrading bacterial strain}

The Bioscreen growth curve analysis instrument was used to determine the effect of different initial concentrations of pinoxaden on the growth of the strain, and the growth curve of bacterial strains efficiently degraded by pinoxaden for $72 \mathrm{~h}$ was plotted (Figure S2). After screening, only strain T4P20-1, strain T4P20-3 and strain T8P20-2 had growth trend under the condition that the initial concentration of pinoxaden was $25 \mathrm{mg} / \mathrm{L}$, and strain T1P20-3 Strain T3P20-1 had a growth trend when the initial concentration of pinoxaden was $50 \mathrm{mg} / \mathrm{L}$. Therefore, the above six strains were selected for follow-up experiments.

\section{Determination of addition recovery rate of highly degrading bacterial strain}

The linear regression equation of pinoxaden herbicide standard is $y=342906 x+41167$, and its correlation coefficient is R2 $=0.9993$. To measure the recovery rate of pinoxaden (Figure S3), which is $92.42 \%-108.26 \%$. The addition recovery of strain meets the requirements of national standard (80 $120 \%$, which proves that the above herbicide extraction and HPLC detection method is feasible.

\section{Determination of degradation rate of highly degrading bacterial strain}

High performance liquid chromatography was used to measure the degradation ability of degrading bacteria in inorganic salt medium, and strains with high degradation rate were screened for subsequent experiments (Fig. 1), strains T4P20-1, T4P20-3 and T6P20-1 had good degradation effect on pinoxaden with an initial concentration of $75 \mathrm{mg} / \mathrm{L}$ within 5 days, and the degradation rates were $93.87 \%, 93.89 \%$ and $97.40 \%$ respectively.

\section{Identification of highly degrading bacterial strain}

Colony morphology of strain T4P20-1 (Fig. 2). Observe the colony morphology of strain T4P20-1 on LB medium. The colony presents milky white, opaque, round, neat edge, smooth surface, raised center, Gram staining is red, and the shape is short rod-shaped bacteria. It is judged that the strain is gram-negative.

Physiological and biochemical reaction results of highly degrading bacterial strains (Table S5). Compared with Dong Xiuzhu's Manual for identification of common bacteria [9] and Ber-ger's Manual for identification of bacteria (Ninth Edition) (Buchanan R.E. et al., 1984), the test results are basically the same.

$1.7 \%$ agarose gel electrophoresis was performed on the amplified products of $16 \mathrm{~S}$ rDNA of the highly degraded strain (Fig. 2), and the size of the gene fragment was about $1400 \mathrm{bp}$. 
The comparison results of blast of strain T4P20-1 on NCBI showed that the 16S rDNA sequence of strain T4P20-1 had high homology with Acinetobacter (Acinetobacter). Combined with the morphological and biochemical identification results, the strain was identified as Acinetobacter pittii. It was submitted to GenBank for login number MW350066. Phylogenetic tree was obtained (Fig. 2).

\section{Determination of growth characteristics of highly degrading bacterial strain}

The growth test results of bacterial strains efficiently degraded by pinoxaden at different $\mathrm{pH}$ values (Fig. 3). The shaking table is $30{ }^{\circ} \mathrm{C}, 160 \mathrm{rpm}$, cultured for 72 hours, and the absorbance values of the strains under the conditions of $\mathrm{pH}=6, \mathrm{pH}=7$ and $\mathrm{pH}=8$ are sampled every 12 hours. The optimum $\mathrm{pH}$ value of strain T4P20-1 is 7. The absorbance value of strain T4P20-1 at $1 \%, 5 \%$ and $10 \%$ inoculum were determined by sampling every $12 \mathrm{~h}$, and the optimal inoculum amount of strain T4P20-1 was $10 \%$ (Fig. 3). Determination results of growth and degradation capacity of bacterial strains efficiently degraded by pinoxaden during incubation time (Fig. 3). The shaking table is $30{ }^{\circ} \mathrm{C}, 160 \mathrm{rpm}$ for 72 hours, and the absorbance value and degradation ability of pinoxaden are measured every 12 hours. The logarithmic growth period of strain T4P20-1 is 12-36 hours on the culture medium of inorganic salt and pinoxaden, and its absorbance value is 0.35 , When strain T4P20-1 was cultured for 72 hours, the concentration of pinoxaden decreased from $75 \mathrm{mg} / \mathrm{L}$ to $5.83 \mathrm{mg} / \mathrm{L}$, and the degradation rate reached $92.23 \%$.

\section{Validation of biodegradation ability of highly degrading bacterial strains by bioassay}

Sensitivity of pinoxaden on maize seed germination (Table 1). The concentrations with significant differences in seed germination rate, bud length and root length were selected for subsequent experiments.

By establishing the linear regression equation of the effect of pinoxaden on the seed germination of subsequent sensitive crops, it was found that pinoxaden had a negative relationship with the germination rate, bud length and root length of subsequent sensitive crops. The sensitive concentrations with significant difference on the germination rate and bud length of corn seeds at the level of $5 \%$ were $75 \mathrm{mg}$ / $\mathrm{L}$ and $100 \mathrm{mg} / \mathrm{L}$. therefore, the pinoxaden with the concentration of $75 \mathrm{mg} / \mathrm{L}$ was selected as the follow-up test. Establish a linear regression equation for the test results (Fig. 4). The sensitive concentration equation of pinoxaden on maize seed germination rate, bud length and root length is $y_{1}=$ $-5.8329 x+104.44$, and the correlation coefficient is $R^{2}=0.9414 ; y_{2}=-0.0893 x+1.956$, correlation coefficient $R^{2}=0.9635 \square y_{3}=-0.0639 x+1.4299$, correlation coefficient $R^{2}=0.9145$, where $y_{1}, y_{2}, y_{3}$ and $x$ represent the germination rate, bud length, root length and pinoxaden concentration of corn seeds respectively.

Changes of germination rate, bud length and root length of maize seeds treated by pinoxaden degradation strain T4P20-1 (Table 2). In the pinoxaden culture medium with an initial concentration of 75 
$\mathrm{mg} / \mathrm{L}$, the bud length of the control group is significantly lower than that of the blank group. After treated with pinoxaden degrading strain T4P20-1, the germination rate and bud length of corn seeds in the treatment group are significantly higher than those in the control group, compared with the control group, The bud length and root length of the treatment group increased by $16.77 \%$ and $5.93 \%$ respectively. With the addition of degrading strains, it can repair the germination of maize seeds.

\section{Whole genome sequencing of degrading bacteria}

A 300 bp library was constructed for each strain. After sequencing on Illumina sequencing platform and data quality control with Trimmomatic(v0.36)software, strain T4P20-1 obtained 6.6×106 original sequences, the number of original bases have $1998,668,400$, the number of sequences after quality control have $6,656,588$, and the number of bases after quality control have $1,996,053,837$. The proportion of bases with sequencing quality of more than 20 was $98 \%$. Before assembly, select the middle highquality sequencing region, take a certain length of $\mathrm{K}$-mer base by base for genome size evaluation, and count that the depth of each $31 \mathrm{~K}$-mer is 132 and the frequency of each depth accounts for $0.46 \%$.

Using SPAdes (v3.13.0) software to assemble the sequencing data of each strain after quality control, the sequence file that can reflect the basic situation of the sample genome is obtained, and the assembly quality is statistically analyzed. Finally, the scaffold sequence greater than $500 \mathrm{bp}$ is selected for subsequent analysis. The results are as follows: the total length of all sequences is $9662835 \mathrm{bp}$; The number of sequences longer than $1200 \mathrm{bp}$ is 139; The total number of scaffold fragments obtained by assembly, if there are chromosomes and plasmids, the total is 364; The maximum sequence length was $627479 \mathrm{bp}$; The shortest sequence length is $208 \mathrm{bp}$; GC content was $36.62 \%$; The number of $n$ is 148 ; The length of scaffold N50 is $178012 \mathrm{bp}$; The length of scaffold N90 is $40279 \mathrm{bp}$.

Prokka(1.13.7) software was used to annotate and predict the bacterial genome. The gene results of strain T4P20-1 were as follows: the total length of predicted genes was 8105181 bp the number of predicted genes was 9350 , and the total length of coding region accounted for $83.88 \%$ of the whole genome.

The software tRNAscan-SE was used to predict the tRNA in the genome, and the software rRNAmmer was used to predict the rRNA in the genome. It was found that strain T4P20-1 had 145 tRNAs, 20 types and 19 rRNAs, including 16S rRNAs have 2, 23S rRNAs have 2 and 5S rRNAs have 15.

Through BLAT alignment, the homologous gene sequence was found in the genome, and then the immature termination codon and frameshift mutation in the gene sequence were found by GeneWise The number of pseudogenes of strain T4P20-1 was 5, there were 3 pre phages, and the total length was $72381 \mathrm{bp}$.

Genomic Island (GI) is a sequence obtained by horizontal transfer. It contains genes related to a variety of biological functions, which can be related to symbiosis or pathogenic mechanism, and the adaptability of organisms. It has an important impact on the evolution of bacteria. Ac-cording to the difference of genes, gene island can be divided into virulence island and metabolic island. Using the obtained genomic gbk 
files, the GI Island sequences contained in the sequenced strains were predicted based on different GI Island prediction software, and the gene island number of strains T4P20-1 was determined as GI_ 1 . The length of gene island is $584230 \mathrm{bp}$ the starting position of gene island is $610554 \mathrm{bp}$ and the ending position of gene island is $26325 \mathrm{bp}$.

Through alignment, a protein sequence can be annotated into a COG, and each COG cluster is composed of lineal homologous sequences, thus the function of the sequence can be inferred. COG database can be divided into 25 categories according to their functions (Fig. 5), and their specific functions are annotated and classified (Table S6). 7961 genes of strain T4P20-1 are an-notated into COG, R: There were 702 genes, accounting for $9.75 \%$, E: amino acid transport and metabolism 714 genes, accounting for $8.97 \%$, $\mathrm{K}$ : transcription 688 genes, accounting for $8.64 \%$.

Statistical results of three categories in GO database (Fig. 5). The T4P20-1 gene of strain T4P20-1 has 36 functions, including 8663 gene orders belonging to biological processes, 1496 gene orders belonging to cell components and 6191 gene orders belonging to molecular functions. Among them, the genes involved in biological processes accounted for the most, including metabolic process $(17.41 \%)$, cellular process $(17.92 \%)$, localization $(4.83 \%)$, biological regulation $(4.08 \%)$, regulation of biological process (3.99\%), and response to stimuli (4.83\%); In cellular function, extracellular region accounted for $0.10 \%$, membrane $7.04 \%$, protein - containing complex $1.13 \%$, and organelle $0.87 \%$; Among the molecular functions, catalytic activity ac-counted for $18.20 \%$, structural molecular activity accounted for $0.71 \%$, binding accounted for $12.79 \%$, transporter activity accounted for $3.29 \%$, and transcription regulator activity accounted for $1.79 \%$.

There were 145 metabolic pathways in strain T4P20-1, and there were 4969 annotated genes, 668 genes for amino acid metabolism (12.24\%), 330 genes for energy metabolism (6.64\%), 330 genes for cofactor and vitamin metabolism (6.34\%). Global and overview Fig. 642 genes (12.92\%) (Fig. 5), KEGG annotation metabolism of carbohydrate metabolism 681 genes (13.70\%) (Table S7), mainly involved in pyruvate metabolism (97 genes), glycolysis/gluconiogenesis (85 genes) and propionic acid metabolism (73 genes).

CAZymes annotation was performed on the protein sequence of the whole genome through crypto-code model search, and the annotated profile of carbohydrate active enzyme genes was obtained (Fig. 5). Strain T4P20-1 obtained 315 carbohydrate related enzymes, of which glycoside hydrolase accounted for $17 \%$, glycosyltransferase accounted for $24 \%$, carbohydrate binding enzyme accounted for $17 \%$ and carbohydrate ase accounted for $24 \%$.

At present, the key enzymes for degrading bacteria to metabolize herbicides include hydrolase, dehydrogenase, decarboxylase, oxidoreductase, ase, cytochrome P450 and so on. In this study, the whole genome of strain T4P20-1 was analyzed, and the gene function was annotated through KEGG, GO, COG, CAZymes, Swiss ProtıPfam $\square$ Interpro Scan and other databases. According to these notes, we screened the relevant degrading enzymes. 
Degradation genes phosphatidylserine decarboxylase $(p s d)$, tRNA ribosyltransferase $(t g t)$, adenylate $5^{\prime}-$ phosphate decarboxylase (pyrF), uroporphyrinogen decarboxylase (hemE), acetal-dehyde phosphate hydrolase ( $p h n X)$, GTP cyclohydrolase (folE) and metal dependent hydrolase (BCG9842IU B0515) were found in strain T4P20-1.

\section{Discussion}

\section{Identification of pinoxaden degrading bacteria}

At present, the research on pinoxaden at home and abroad mainly focuses on the determination of its residue and weed control effect. It is reported that the residue of pinoxaden is determined by HPLC-MS and HPLC. Zhu Wenda, Ma Bo and others [10-12] studied the control effect of pinoxaden on weeds in wheat field, However, the research on the degradation of pinoxaden is still blank. In this study, a strain Acinetobacter pittii was screened from the long-term polluted soil. Strain T4P20-1 had a degradation rate of $93.87 \%$ for pinoxaden with an initial concentration of $75 \mathrm{mg} / \mathrm{L}$ in 5 days, which was the first report. Most of the existing literatures reported the research on the remediation of oil pollution by Acinetobacter, but there were few reports on the degradation of herbicides in soil by Acinetobacter. Yang Fengshan et al. [12] found that the degradation rates of pinoxaden with initial concentrations of $500 \mathrm{mg} / \mathrm{L}$ and $5 \mathrm{mg} / \mathrm{L}$ were $28.76 \%$ and $85 \%$ respectively after 7 days of cultivation of Acinetobacter sp. TOB1.

\section{Growth and degradation characteristics of pinoxaden degrading bacteria}

Because the individual of bacteria is small and difficult to observe, the growth and repro-duction of bacteria are usually judged by the number of colonies. Many studies have shown that the growth of bacteria is affected by many external environmental factors, including carbon source, nitrogen source, inorganic salt, growth factor, temperature, humidity, $\mathrm{pH}$, etc. [13-18]. Bacteria also play different roles under different environmental conditions, such as fuel and food processing industry, environmental recycling and purification, pharmaceutical production, etc. [19-22]. This paper mainly studies the bacteria with pesticide degradation ability. According to the data, its degradation ability is also affected by external environmental factors $[23,24]$. In order to find out the optimal growth and degradation ability of high-efficiency degrading bacterium T4P20-1 under the influence of other external factors, the corresponding experiments were made. The purified T4P20-1 single colony was cultured at different $\mathrm{pH}$, inoculation amount and culture time, and the optimal conditions were obtained through the test results.

\section{Validation of the degradation ability of pinoxaden degrading bacteria}

In order to improve crop yield in the field, a series of pesticides, such as insecticides, fungicides, herbicides, cochides, rodenticides and nematocides, have been widely used, but pesticides can also cause 
damage to crops to varying degrees in the process of pesticides and pesticides [25-27]. The composition of pesticides and the concentration of pesticides applied will have a certain impact on the growth of crops $[28,29]$. Applying pinoxaden moiety grass pesticides so this article explores the size concentration is sensitive to the wheat-rice crop seed corn growth, with the in-crease of concentration of pinoxaden moiety grass pesticides, sensitive crops of corn seed germination in the wheat-rice cropping the impact is bigger, the but again to join pinoxaden moiety of grass pesticides after sensitive crop seed corn stubble after adding T4P20-1 high efficiency degradation bacterium, The germination of maize seeds of the latter sensitive crops was improved to a certain extent, and it was concluded that when the concentration of pinoxaden pesticide was $75 \mathrm{mg} / \mathrm{L}$, the germination rate of maize seeds of the latter sensitive crops was higher, and the growth of bud length and root length was better. Therefore, the highly efficient bacterial strain T4P20-1 plays an important role in the degradation process.

\section{Degradation genes of pinoxaden efficient degradation bacterial strain}

The main reason bacteria can degrade depends on their composition [30]. In order to explore the internal degradation mechanism of the highly degrading bacterial strain T4P20-1 screened in this experiment, the genome sequencing results were analyzed, and the degradation genes in strain T4P20-1 were predicted to be psd, tgt, pyrF, hemE, phnX, folE, BCG9842 I U B0515.

\section{Conclusion}

In this experiment, strain T4P20-1 with pinoxaden as the only carbon and nitrogen source was domesticated and isolated, and identified as Acinetobacter pittii, the serial number on GenBank is MW350066. Through the test to determine the effects of different $\mathrm{pH}$ value, inoculation amount and culture time on the growth of strain T4P20-1, it is concluded that when its $\mathrm{pH}=7$ and the inoculation amount is $10 \%$, the concentration of pinoxaden decreases from $75 \mathrm{mg} / \mathrm{L}$ to $5.83 \mathrm{mg} / \mathrm{L}$ at $72 \mathrm{~h}$, and the degradation rate reaches $92.23 \%$. The degradation effect is verified by the germination of sensitive corn seeds, and the results show that: the higher the addition con-centration of pinoxaden, the lower the germination rate of corn seeds and the shorter the bud length and root length. However, after the addition of degrading strain, the germination rate, bud length and root length of corn seeds increased significantly, so the highly degrading bacterial strain T4P20-1 can repair the pesticide pollution of pinoxaden. The whole genome framework of the strain was obtained by gene sequencing, and the genome of strain T4P20-1 The total length of predicted genes was $8105181 \mathrm{bp}$ the number of predicted genes was 9350 , and the total length of coding region accounted for $83.88 \%$ of the whole genome. Strain T4P20-1 annotated through databases such as cog, GO, KEGG and CAZymes, and predicted relevant genes related to herbicide degradation. In conclusion, the strains screened in this study have certain remediation effects on soil contaminated by pinoxaden. 


\section{Declarations}

Acknowledgements This work was supported by Key Laboratory of Molecular Biology and Key Laboratory of Microbiology, College of Heilongjiang Province.

Author Contributions Conceptualization: F.Y. and W.Z.; Methodology: F.Y. and C.L.; Software: C.S. and Y.W.; Validation: C.S., Y.W., C.L., and F.Y.; Formal analysis: F.Y., M.Y., and Y.W.; Investigation: C.L., H.F., and C.S.; Resources: C.L. and C.S.; Data curation: Y.W. and C.S.; Writing-original draft preparation: C.S. and F.Y.; Writing-review and editing: Y.W., and C.L.; Visualization: Y.W., and C.S.; Supervision: F.Y., H.F., and C.L.; Project administration: F.Y. and C.L.; Funding acquisition: F.Y. All authors have read and agreed to the published version of the manuscript.

Funding This research was funded by the National Key Research and Development Program of China (grant number 2017YFD0201703), the Heilongjiang Natural Science Foundation Research Team Project (grant number TD2019C002), and the University Nursing Program for Young Scholars with Creative Talents in Heilongjiang Province (grant number UNPYSCT 2017119).

Data Availability The data presented in this study are openly available on FigShare at doi: xxx.

Code Availability Yes.

Conflict of interest The authors declare that they have no conflict of interest.

Consent to Participate Informed consent for participation was obtained from all participants included in this study.

Consent for Publication Yes.

Ethical Approval There are no ethical issues involved in this study.

\section{References}

1. Han HD, She YX, He YJ et al (2020) Simultaneous determination of residues of pinoxaden, acetylene and detoxine in Barley by high performance liquid chromatography-tandem mass spectrometry. Food Sci 41:292-297 (in Chinese)

2. Ou J, Liu KL, Ou XM et al (2020) Determination of pinoxaden residue in water and soil by high performance liquid chromatography. Pesticides 59:901-905 (in Chinese)

3. Yang G (2011) Characters and application of pinoxaden. Pesticide Market Information 0:38 (in Chinese)

4. Dian C, Wu SR, Xue HA et al (2020) Stereoselective catabolism of compounds by microorganisms: Catabolic pathway, molecular mechanism and potential application. Int Biodeterior Biodegrad 146:104822-104834 
5. Adolfo M, Esteban FD (2018) A review on pesticide removal through different processes. Environ Sci Pollut Res 5:2051-2064

6. Tan X, Zhang XD (2019) Observation and differentiation of bacteria by Gram staining. Biology Teach 44:71-72 (in Chinese)

7. Sarlak Z, Khosravi DK, Rouhi M et al (2021) Bioremediation of organophosphorus pesticides in contaminated foodstuffs using probiotics. Food Control 126:108006-108018

8. Buchanan RE, Gibbons NE et al (1984) Berger handbook of Bacterial Identification (eighth edition). Science Press. (in Chinese)

9. Dong XZ, Cai MY (2001) Handbook of Systematic Identification of Common Bacteria. Science Press. (in Chinese)

10. Yang L, Chen K, Wang BN, Liao CX, Wei J, Xie Y (2020) Determination of pinoxaden and alkynyl in water by high performance liquid chromatography-tandem mass spectrometry. Chem Anal Meas 29:15-18 (in Chinese)

11. Li QM, Li SZ, Zhang YH, Li C, Lu ZX, Chi XC, Fu Y (2021) Control effect and safety evaluation of $4 \%$ pinoxaden and difluorosulfochlor OD on weeds in wheat field. J Anhui Agricultural Sci 49:128-165 (in Chinese)

12. Yang FS, Sun C, Tang RY, Ma YK, Fu HY, Liu CG (2020) Screening and degradation capacity determination of two strains of benzotrone degrading bacteria. Chin J biology 37:55-58 (in Chinese)

13. Nuran Y, Yakup SV (2020) Effects of processing and storage on pesticide residues in foods. Crit Rev Food Sci Nutr 60:3622-3641

14. Zaranyika MF, Matimati E, Mushonga P (2020) Degradation kinetics of DDT in tropical soils: A proposed multi-phase zero order kinetic model that takes into account evaporation, hydrolysis, photolysis, microbial degradation and adsorption by soil particulates. Sci Afr 9:467-479

15. Maitra S (2021) DBP biodegradation kinetics by Acinetobacter sp.33F in pristine agricultural soil. Environ Technol Innov 21:101240

16. Muhammad S, Muhammad U, Abdul W et al (2020) Terrestrial ecosystem functioning affected by agricultural management systems: A review. Soil Tillage Res 196:104464-104474

17. Santillan JY, Rojas NL, Ghiringhelli PD et al (2020) Organophosphorus compounds biodegradation by novel bacterial isolates and their potential application in bioremediation of contaminated water. Bioresour Technol 317:124003-124045

18. Shardendu K, Garima K, Mohd AD et al (2018) Microbial Degradation of Organophosphate Pesticides: A Review. Pedosphere 28:190-208

19. Shalini V, Dharam S, Subhankar C (2020) Biodegradation of organophosphorus pesticide chlorpyrifos by Sphingobacterium sp. C1B, a psychrotolerant bacterium isolated from apple orchard in Himachal Pradesh of India. Extremophiles 24:897-908

20. Zhang YX, Xu ZX, Chen ZJ et al (2020) Simultaneous degradation of triazophos, methamidophos and carbofuran pesticides in wastewater using an Enterobacter bacterial bioreactor and analysis of 
toxicity and biosafety. Chemosphere 261:128054-1228062

21. Singh S, Kumar V, Gill JPK et al (2020) Herbicide Glyphosate: Toxicity and Microbial Degradation. Int J Environ Res Public Health 17:7519-7536

22. Pan LW, Siegrist RL, Crimi M (2012) Effects of In Situ Remediation Using Oxidants or Surfactants on Subsurface Organic Matter and Sorption of Trichloroethene. Groundw Monit Remediation 32:96-105

23. Zhen MN, Song BR, Liu XM et al (2018) Biocharmediated regulation of greenhouse gas emission and toxicity reduction in bioremediation of organophosphorus pesticide contaminated soils. Chin J Chem Eng 26:2592-2600

24. Soares PRS, Birolli WG, Ferreira IM et al (2021) Biodegradation pathway of the organophosphate pesticides chlorpyrifos, methyl parathion and profenofos by the marine-derived fungus Aspergillus sydowii CBMAI 935 and its potential for methylation reactions of phenolic compounds. Mar Pollut Bull 166:112185-112196

25. Zhao SM, Xu W, Zhang WL et al (2021) In depth biochemical identification of a novel methyl parathion hydrolase from Azohydromonas australica and its high effectiveness in the degradation of various organophosphorus pesticides. Bioresour Technol 323:124641-124650

26. Jay $P$ et al (2014) Pesticide relevance and their microbial degradation: a-state-of-art. Reviews in Environmntal Science and Biotechnology 13:429-466

27. Ye XL, Dong F, Lei XY (2018) Microbial Resources and Ecology Microbial Degradation of Pesticides. Nat Resour Conserv Res 1:22-28

28. Zhang $H$, Yuan $X$, Xiong $T$ et al (2020) Bioremediation of co-contaminated soil with heavy metals and pesticides: influence factors, mechanisms and evaluation methods.Chemical Engineering Journal:125657

29. Singh AK, Flounders AW, Volponi JV et al (1999) Development of sensors for direct detection of organophosphates. Part I: Immobilization, characterization and stabilization of acetylcholinase and organophosphate hydrolase on silica supports. Biosens Bioelectron 14:703-713

30. Kumar S, Kaushik G, Dar MA et al (2018) Microbial Degradation of Organophosphate Pesticides: A Review. Pedosphere 28:190-208

\section{Tables}

Table 1. Bioassay results of the sensitive concentration of maize seed to pinoxaden in the last sensitive crop 


\begin{tabular}{llll} 
Concentration of pinoxaden $(\mathrm{mg} / \mathrm{L})$ & Budding rate $(\%)$ & Buds long $(\mathrm{cm})$ & Root length $(\mathrm{cm})$ \\
\hline 0 & $93.33 \mathrm{a}$ & $2.33 \mathrm{a}$ & $1.08 \mathrm{a}$ \\
\hline 5 & $91.67 \mathrm{a}$ & $2.17 \mathrm{ab}$ & $1.02 \mathrm{a}$ \\
\hline 25 & $88.33 \mathrm{ab}$ & $2.01 \mathrm{abc}$ & $0.98 \mathrm{a}$ \\
\hline 50 & $84.17 \mathrm{ab}$ & $1.96 \mathrm{abc}$ & $0.85 \mathrm{a}$ \\
\hline 75 & $79.17 \mathrm{bc}$ & $1.71 \mathrm{bc}$ & $0.72 \mathrm{a}$ \\
\hline 100 & $72.50 \mathrm{c}$ & $1.67 \mathrm{c}$ & $0.54 \mathrm{~b}$
\end{tabular}

Duncan method is used for significance analysis. Each column contains different letters, indicating that the difference is significant, and the difference is at the significant level of 0.05 .

Table 2. Seed germination test results of pinoxaden after strain treatment

\begin{tabular}{llll} 
Group & \multicolumn{3}{l}{ Maize seeds treated with pinoxaden by strain } \\
\cline { 2 - 4 } & The budding rate $(\%)$ & Buds long $(\mathrm{cm})$ & Root length $(\mathrm{cm})$ \\
\hline The blank group & $93.33 \mathrm{a}$ & $2.33 \mathrm{a}$ & $1.08 \mathrm{a}$ \\
\hline The control group & $72.50 \mathrm{a}$ & $1.67 \mathrm{~b}$ & $0.54 \mathrm{a}$ \\
\hline Treatment group & $83.33 \mathrm{~b}$ & $1.95 \mathrm{ab}$ & $0.86 \mathrm{a}$
\end{tabular}

Duncan method is used for significance analysis. Each column contains different letters, indicating that the difference is significant, and the difference is at the significant level of 0.05 .

\section{Figures}
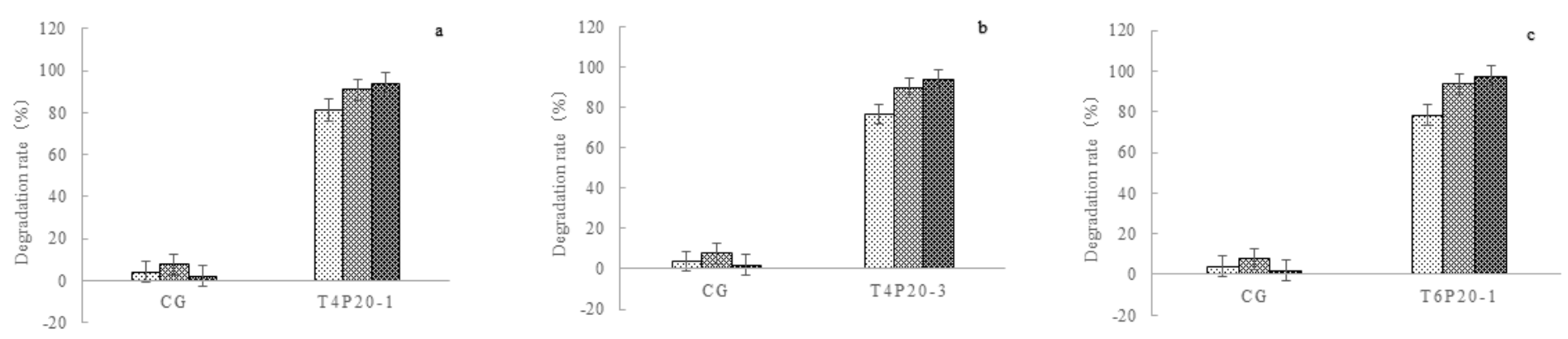

Figure 1. Degradation rate of pinoxaden by degrading strain. (a), (b) and (c) represent the degradation rates of different concentrations of pinoxaden by T4P20-1, T4P20-3 and T6P20-1 respectively. ( : $: 25 \mathrm{mg} / \mathrm{L} ;: 50 \mathrm{mg} / \mathrm{L} ;: 75 \mathrm{mg} / \mathrm{L}$ ).

\section{Figure 1}


See image above for figure legend.
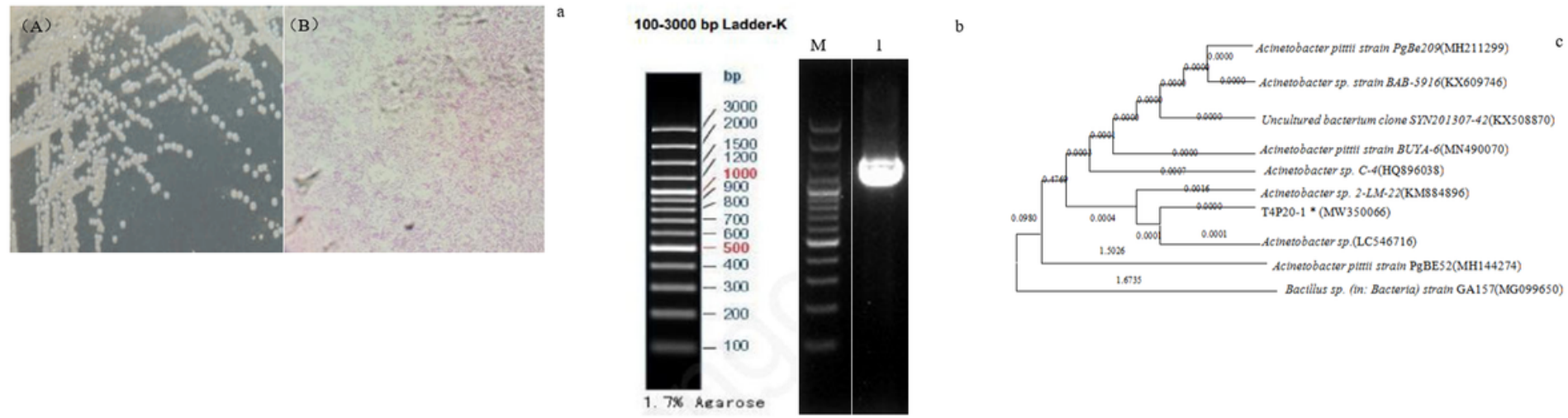

\section{Figure 2}

Identification of species of bacteria. ((a) Morphological identification of highly degrading bacterial strain T4P20-1. (A): Optical microscope; (B): Gram stain. (b) Agarose electrophoresis of 16S rDNA of a highly degrading bacterial strain T4P20-1. M: marker DL2000; 1: 16S PCR product. (c) Phylogenetic tree of strain T4P20-1.)
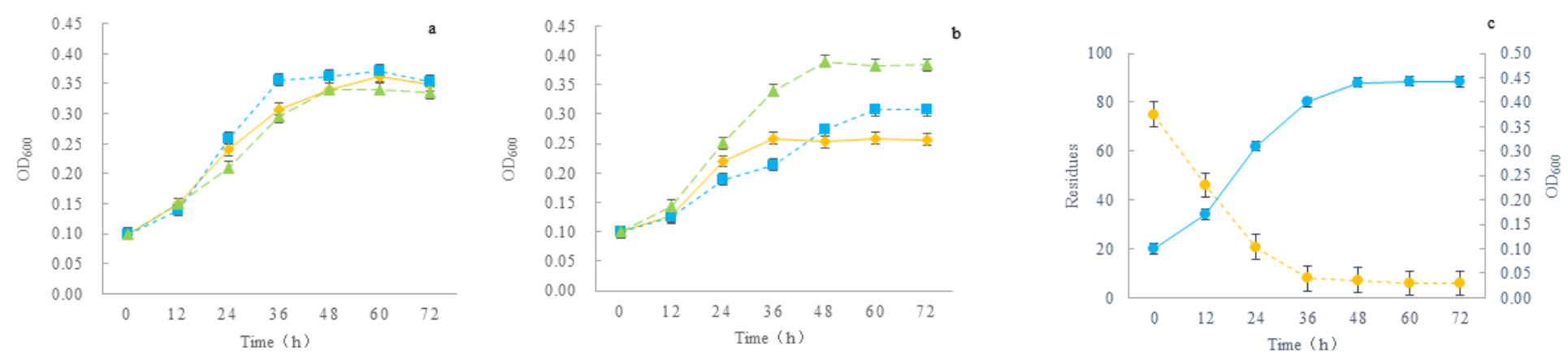

Figure 3. (a), (b) and (c) were the growth measurements of bacterial strain T4P20-1 with high efficiency of pinoxaden degradation at different $\mathrm{pH}$ values, inoculation amount and culture time, respectively. ((a): $\square-\mathrm{pH} 6.0 ; \cdots \cdots \cdots$

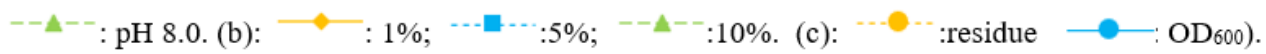

Figure 3

See image above for figure legend. 

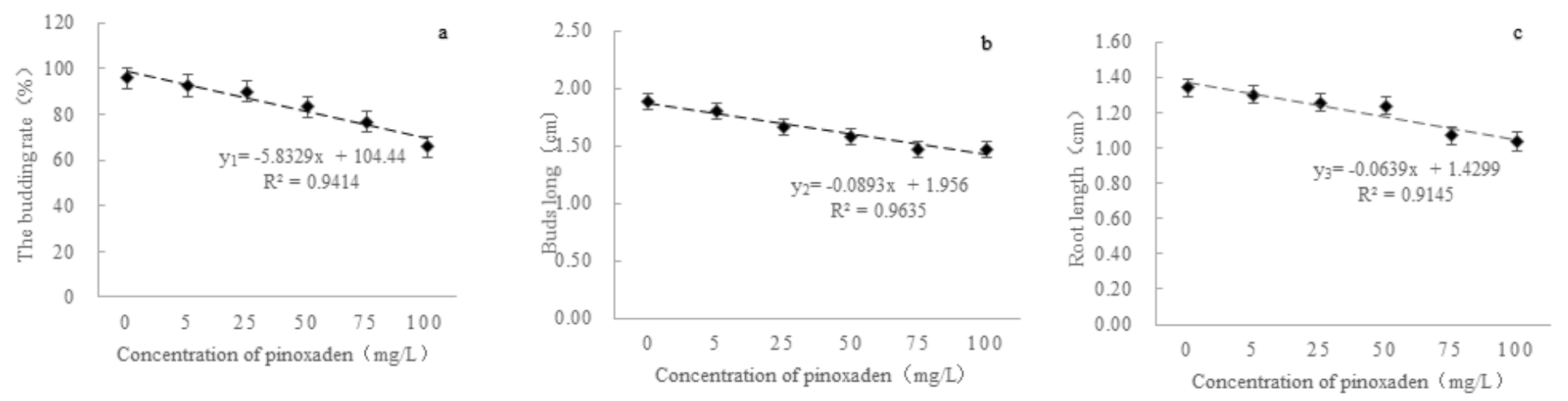

\section{Figure 4}

Identification of species of bacteria. ((a) Morphological identification of highly degrading bacterial strain T4P20-1. (A): Optical microscope; (B): Gram stain. (b) Agarose electrophoresis of 16S rDNA of a highly degrading bacterial strain T4P20-1. M: marker DL2000; 1: 16S PCR product. (c) Phylogenetic tree of strain T4P20-1.) 

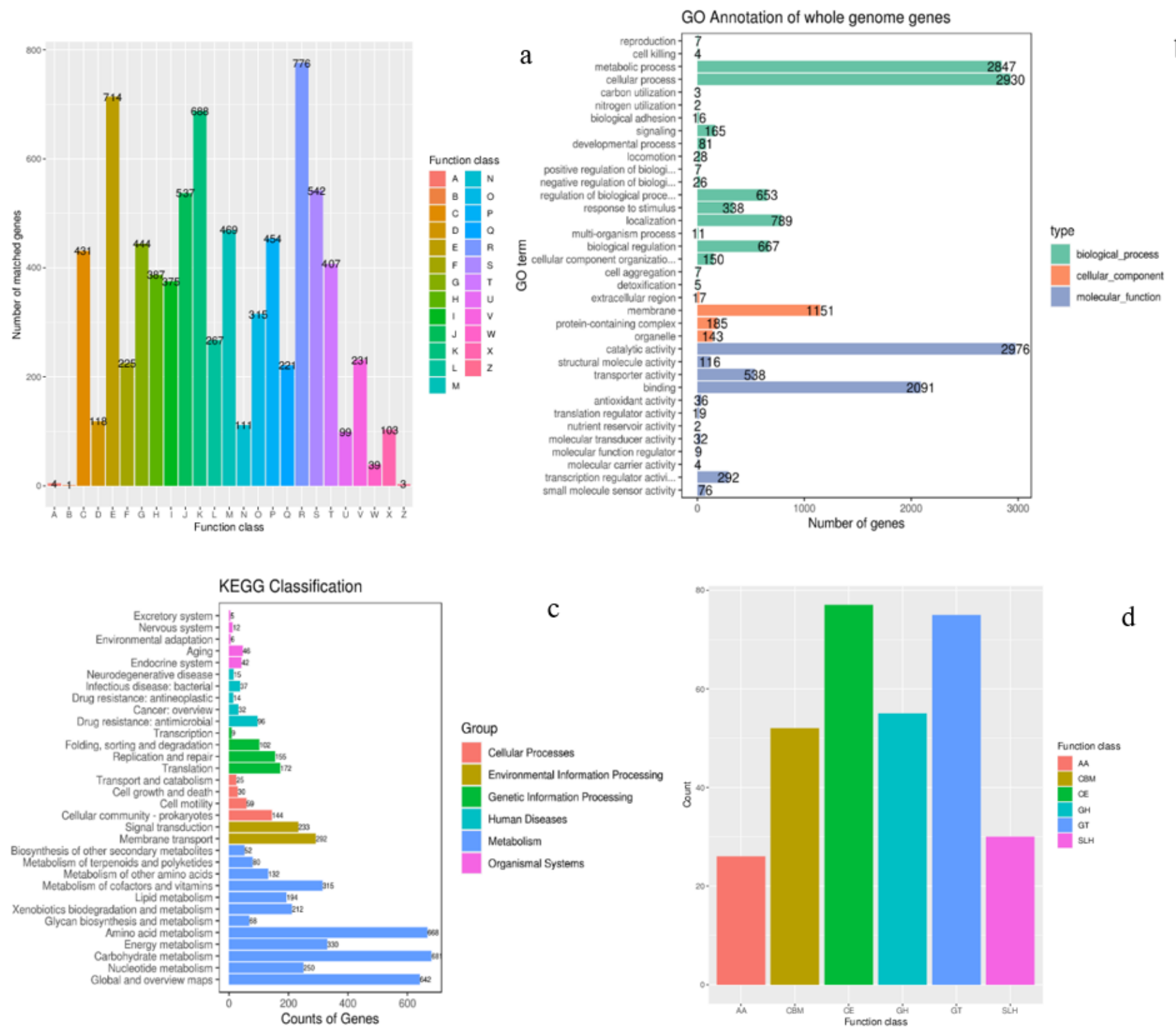

Figure 5

Whole genome sequencing of degrading bacteria. ((a) COG functional annotation classification of strain T4P20-1. (b) Go functional annotation classification of strains. (c) KEGG functional annotation classification of strains. (d) CAZymes functional annotation classification of strains.)

\section{Supplementary Files}

This is a list of supplementary files associated with this preprint. Click to download.

- Supplementarydata.docx

- Authorchecklist.docx 